Perceptions of police use of force: The importance of trust

\begin{tabular}{|r|l|}
\hline Journal: & Policing: An International Journal \\
\hline Manuscript ID & PIJPSM-07-2020-0111.R1 \\
\hline Manuscript Type: & Research Paper \\
\hline Keywords: & Police use of force, trust in police, police legitimacy, police tactics \\
\hline \multicolumn{2}{|l}{} \\
\end{tabular}


Police use of force

\section{Perceptions of police use of force: The importance of trust}

The range of tactical force options available to police is increasing, while public debate about police use of force is never far from the headlines. But what factors shape how people accept police use of force? We use two online experiments to test whether different force options affected judgements about the acceptability of police action, and to explore the role of trust and legitimacy in people's judgements. We found across both studies that respondents judged scenarios involving a weapon (baton, CS spray, Taser) as less acceptable compared to scenarios that did not (talking down, handcuffs); but they did not draw much distinction between the specific weapon used. In Study 1, exposure to different police tactics had no effect on trust and legitimacy. In Study 2, prior perceptions of trust were strong predictors of acceptability judgements.

Theoretical and practical implications are discussed.

Keywords: police use of force, trust, legitimacy, police tactics 
Police use of force

\section{Introduction}

The ways police use force, when, and against whom, are perennial but also currently topical questions. In response to the killing of George Floyd by Minneapolis police officer Derek Chauvin, a great deal of public and scholarly attention has recently, and unsurprisingly, focused on police use of force in the US (Nix, 2020). The orientations and structures that sustain police use of force, and public reactions to it, are by contrast comparatively under-studied in the British context. Among many other lacuna, there is a paucity of empirical research examining public attitudes toward different use of force resolutions by British police. In this paper we explore how use of force affects views of police at a time in which the nature and scope of force applications, how these are understood, and indeed the basic enterprise of policing itself is being reconsidered.

As is well known, and unusually from an international perspective, British police operate largely unarmed. Moreover the application of force by officers is relatively rare. In the year ending March 2019, 610 people were seriously injured after contact with police (2\% of all injuries reported; Home Office, 2019a). Firearms were discharged only 13 times (out of the 4,500 occasions they were used; Home Office, $2019 \mathrm{~b}$ ), and in only $11 \%$ of 23,000 recorded incidents involving Tasers ${ }^{1}$ was the Taser actually discharged (Home Office, 2019a) ${ }^{2}$. Yet, incidents that do occur can generate significant dispute and tension. On the one hand, given a policing ideology that revolves around notions of consent, an unarmed constabulary, and policing with the public (Bowling et al., 2019), it may be that some people react strongly to incidents that transgress these norms. On the other hand, this ideology arguably obscures the fact that policing is ineluctably linked to the application of force

\footnotetext{
${ }^{1}$ In this paper - and in the vignettes - we use the brand name Taser to refer to any conducted energy devise, given the widespread usage of this term.

${ }^{2}$ Discharges refers to incidents where the Taser was 'fired'; drive-stun and angle-drive stun are not included in this figure.
} 
Police use of force

(Brodeur 2010), and for certain groups in society forceful, aggressive, policing is far from a rarity (Lammy 2017). Current political developments, particularly around the Black Lives Matter movement, have served to highlight these tensions.

Moreover, in contrast to the idea of the unarmed constabulary, recent growth in violent offending, cuts to officer numbers, and the advent of new technology such as Taser have raised the temperature around questions of officer safety, when it is appropriate to use force, and the variety of tactics available to street level officers (College of Policing, 2020). At a time when there is a push to give police a wider range of tactical force options (in many constabularies officers now carry baton, $\mathrm{CS}$ spray $^{3}$ and Taser), little is known about the effect new force modalities might have on public opinion. In particular, it is not clear whether people distinguish between different tactics and find some less acceptable than others.

How do people judge police use of force? Why might some support police in a particular instance, while others oppose them? A small but growing body of research has explored public trust and police legitimacy as two critical factors shaping public attitudes towards police use of force (Bradford et al., 2017; Gerber and Jackson, 2017; Johnson and Kuhns, 2009; Milani, 2020). This research shows that trust and legitimacy can generate support for the normatively justified, limited, use of force. Unwarranted and unjustified force, however, which exceeds the limits of police authority (c.f., Trinkner et al., 2017), seems to negate this effect (see for example Bradford et al., 2017) and risks undermining trust and legitimacy. A substantial body of literature documents the significant cost associated with violent and aggressive policing on public trust and perceptions of legitimacy (e.g., Perry et al., 2017).

\footnotetext{
${ }^{3}$ CS spray is a type of chemical incapacitating spray, more widely known as 'irritant spray'. Most police forces in England and Wales now use PAVA (Pelargonic Acid Vanillylamide), which is another type of irritant spray.
} 
Police use of force

In this paper we use two online experiments to examine how judgements about police use of force are influenced by underlying perceptions of trust and legitimacy. We also consider the reverse - whether and how assessments of legitimacy and trust are themselves influenced by hearing about police use of force. At what threshold does force become unjustifiable in people's minds, particularly in relation to the different tactics or modes of delivery available to police. As awareness of police use of force proliferates, increasingly captured and disseminated by and to the public via mobile phones, police body-worn cameras and CCTV, it is critical to examine the effect these incidents have on public opinion.

\section{Police Trust and Legitimacy and Judgements of Police Behavior}

Perceptions of police are premised on a wide range of factors, including interactional components (Oliveira et al., 2019), ideological beliefs (Silver and Pickett 2015), and psychological orientations (Bradford et al., 2017), as well as other identity and political antecedents (Gerber and Jackson, 2017; Radburn et al., 2018; Roché and Roux, 2017). Loader and Mulcahy (2003), for example, have argued that for significant sections of the British population, perceptions of police are characterized by an often romantic and nostalgic quality revolving around a particular set of cultural beliefs where the police signify 'order' and 'justice'.

The close association between the police and ideas of justice and order may function as a heuristic (Kahneman, 2011): a cognitive shortcut through which large sections of the population intuitively judge police as arbiters of moral conduct. On this account, police action is defined as 'good' and appropriate by default; people judge specific police behaviors according to a deep-seated set of assumptions that police are intrinsically 'good' and behave 
Police use of force

appropriately. ${ }^{4}$ Building on these ideas, Bradford and colleagues (2017) model heuristic judgements in terms of police legitimacy and public trust as aspects of people's opinions that generate support, encourage decision-acceptance, and as intimately bound up with deference, compliance, and a moral duty to obey (Tyler, 2006; Tyler and Huo, 2002). In other words, those who believe that police behavior is aligned with societal expectations regarding the appropriate use of power - that police generally "do the right thing" for the right reasonswill also tend to judge specific police actions positively (Bradford et al., 2017, p. 623). Thus, people may justify police violence to the extent that they generally justify police.

\section{Defining Legitimacy and Trust}

As is increasingly common, in this paper we distinguish between two components of police legitimacy: normative alignment and duty to obey (Trinkner et al., 2018). Normative alignment refers to perceptions of whether the police act and behave in accordance with societally shared moral values (i.e., the perceived value congruence between the individual and the police; Gerber and Jackson, 2017). Duty to obey is more akin to a 'deferent stance' towards the institution, whereby people feel a moral obligation to obey the police and grant them the right to dictate appropriate behavior, including when and how to use force (Gerber and Jackson, 2017). Both components are reflexive and may be withdrawn, renegotiated or attenuated as individuals evaluate police behavior; but, equally, both comprise relatively stable aspects of people's orientations toward police that affect how they judge police actions.

Like legitimacy, trust in the police is also a reflexive concept, which is constantly being revaluated and held up against established norms of probity and fairness (Bradford et al., 2017). Trust is based on judgements of efficacy and competence, but also upon

\footnotetext{
${ }^{4}$ To be sure, this is far from the reality for many of those governed by police, in countries across the world; especially people of colour, migrants, those under some form of carceral supervision, and other vulnerable groups.
} 
Police use of force

expectations that police will treat members of the public in appropriate ways. In this paper, we consider trust according to three dimensions: assessments of fairness, effectiveness, and bounded authority (Trinkner et al. 2018). Broadly, these comprise expectations and evaluations of police motives (e.g., that police treat people fairly and not exceed their authority) and competency (e.g., that police will turn up if called in an emergency).

There is, of course, disagreement within the field regarding the concepts and causal relationships within this process-based model of policing; for example, the extent to which procedural justice, trust and legitimacy are separate constructs (Tyler, 2006; Jonathan-Zamir et al., 2015), the extent to which the relationships between these three constructs are causal (Nagin and Telep, 2017), the measurement and operational definitions of key terms within this framework (Tankebe, 2013), and the lack of adequate attention to the social and cultural context within which this framework operates (Tankebe, 2009). But our decision to treat trust and legitimacy as distinct theoretical constructs, and to use perceptions of effectiveness and fairness as measures of trust is not new, and has been supported in a plethora of observational, experimental and other forms of empirical and indeed theoretical study (e.g. Jackson et al. 2013; Jackson and Gau 2016; Stoutland 2001).

Alongside trust and legitimacy, an important additional factor is identification with police as members of one's 'in-group', which has been shown to be closely associated with both trust and legitimacy (Tyler and Huo 2002; Bradford et al. 2014). At the most basic level, if we view police officers as being like ourselves, we are more likely to trust and hold them legitimate (Bradford et al. 2014). While the dynamics of this relationship are likely to be complicated - for example, does identification precede or flow from trust judgements - the concept of identification with police seems particularly pertinent given current debates about representation within the service. It also serves as a reminder that both trust and legitimacy 
Police use of force

are relational in character, and are generated and sustained via processes of identification (Radburn et al. 2018).

\section{Trust, legitimacy and 'reading' police actions}

Central to the concepts of trust and legitimacy is the idea that those who are trusted, and who command legitimacy, are enabled and empowered to act on the behalf of those they govern. Although previous research has documented that both are important for predicting support for police actions, decisions and directives (Bolger and Walters, 2019; Jackson et al., 2013; Tyler and Huo, 2002; Yesberg and Bradford, 2019), little research has considered how trust and legitimacy influence perceptions of police use of force, nor considered whether and why one, rather than the other, might be a more important influence on the way police actions are read.

The few studies that do exist have found positive associations between trust, legitimacy, and support for police use of force (Bradford et al., 2017; Gerber and Jackson, 2017). In a representative survey of UK adults, Bradford and colleagues (2017) found that beliefs about police legitimacy were associated with the acceptance of police use of force, but only where it appeared prima facie justifiable. Gerber and Jackson (2017) similarly found that legitimacy generates support and authorization for the police use of force in the US, again as long as this falls within socially acceptable limits. These studies suggest that to the extent people believe, in a general sense, that police are legitimate authorities, they also tend to judge specific police decisions and activities as legitimate, just and proper, as long as these actions appear constrained within certain normative bounds (also see Milani, 2020).

Naturally, there are other reasons why people may support or oppose police use of force. Silver and Pickett (2015) distinguish between what they term utilitarian concerns, such as fear of crime, and symbolic beliefs, such as religiosity, retributiveness and (writing in the US) beliefs about gun control and racial prejudice. Importantly, they also consider the effect 
Police use of force

of political ideology, finding that conservatives are more supportive of police use of force than moderates or liberals. Other research has similarly found that more punitive, authoritarian and conservative ideologies predict more support for use of force (Gerber and Jackson, 2017; Roché and Roux, 2017). Milani (2020) considered how political ideologies shape support for the use of force in the US and found belief in a just world and authoritarian orientations, or so-called 'system-justifying' belief systems, predicted support for excessive use of force. Using direct measures of authoritarian attitudes and just world beliefs as measures of people's fundamental political ideologies, in this paper we consider whether such ideologies shape support for police in general, and the use of force in particular.

\section{The effects of police use of force on public opinion}

While previous studies demonstrate that trust, legitimacy and other attitudes can generate support for normatively limited use of force, a substantial body of literature also documents the significant costs associated with violent and aggressive policing (c.f., Bradford et al., 2014; Jackson et al., 2013). Tyler (2011, pp. 256-257), for example, describes how the New York City Police Department's stop-and-frisk practices, considered by many as "harassing and degrading", impeded compliance and voluntary cooperation with police, and undermined both legitimacy and trust. Milani (2020) found that while the use of unjustified force resulted in a deterioration of trust in and normative alignment with police.

The idea that police use of force incidents damage trust and legitimacy is arguably more prevalent in discussions of policing than the position outlined above (that trust and legitimacy shape how such incidents are viewed in the first place). Therefore we also examine whether hearing about police use of force affects trust and legitimacy. Specifically, by examining the effect of different types of use of force resolutions while holding constant the other characteristics of the encounter, we test what some of the normative bounds for the application of force might be. Do different tactics — unarmed techniques, baton, CS spray, 
Police use of force

Taser - have differential effects on subsequent trust and legitimacy judgements, particularly when compared with non-violent resolutions to the same situation? As noted, this is an issue of particular policy concern in England and Wales at present, most pertinently because an apparent increase in violent crime, and an increase in assaults on officers (College of Policing, 2020), has led to calls for the issuing of Tasers to more or even all 'street-level' police. Use of Tasers has increased markedly in recent years, with incidents increasing in number from 16,913 in 2017/18 to 23,451 in 2018/19 alone (Home Office, 2019a). It seems almost certain that incidents which would previously have been dealt with via physical restraint or baton use are now being resolved via drawing, pointing or discharging a Taser, making judgements about use of this force option vis a vis others a particularly important question.

\section{The Present Studies}

We conducted two online experimental studies. We used a text-based vignette describing an incident involving someone suspected of carrying a knife who disobeys police instructions. We manipulated: (1) the tactic through which the police officer resolved the situation (talking down, handcuffs, baton, CS spray, Taser); and (2) whether force was actually used or simply threatened (e.g., Taser drawn and the suspect 'red-dotted' with the laser sighting). In Study 1, we explored whether exposure to different police officer tactics was accompanied by a concomitant loss of trust and legitimacy. Although the vignettes present a hypothetical scenario, previous research has shown that varying officer behavior through text-based vignettes can successfully shift participants' judgements of, for example, police legitimacy (e.g. Silver, 2020). In Study 2, we tested whether people's prior perceptions of the police predicted their judgements about police use of force. We specify three over-arching hypotheses. 
Police use of force

H1: Tactics that involve use of force with a weapon (baton, CS spray, Taser) will be less acceptable to people than those that involve no weapon or no force at all (talking down, handcuffs). We make no prediction about whether a distinction will be made between the different weapons used (e.g., baton vs. Taser), given the lack of prior research on this topic [Studies 1 and 2]

H2: Compared to unarmed and no-force scenarios, exposure to a scenario where armed tactics are used will result in a loss of trust and legitimacy [Study 1]

H3: People who trust the police and grant them legitimacy will be more accepting of police use of force[Study 2]

\section{General Method}

\section{Recruitment of Participants}

Both studies were hosted on Qualtrics. Residents of England and Wales were recruited via the online crowdsourcing platform Prolific. In line with Prolific recruitment protocols, participants received compensation for their time. We followed Chandler and Paolacci's (2017) advice on how to minimize participant fraud on Prolific: we set constraints so that participants could only take the survey once and included attention checks throughout the surveys. Participants were excluded if they got more than one attention check wrong.

\section{Procedure and Materials}

In both studies, participants were presented with a short vignette about an encounter between a police officer and a person suspected of concealing a weapon. We conducted a pilot study with 302 participants which confirmed the credibility of the scenario $(85 \%$ of participants thought the scenario was plausible and 73\% thought it included enough information for them to make a judgement about it). The pilot study also indicated that it was 
Police use of force

most sensible, for our purposes, to use a scenario that provided no information about whether or not the suspect was actually concealing a weapon.

Both studies employed a 4 (police tactic) x 2 (use of force) between-subjects design. Participants were randomly allocated to one of four police tactic conditions in which the officer resolved the situation using either: handcuffs, baton, CS spray, or Taser; and to one of two use offorce conditions: actual use of force or the threat to use force. We also included an additional reference category where the officer resolved the situation by 'talking down' the suspect. There was only one version of the talking down vignette because use of force was not applicable in this scenario.

Therefore, participants were randomly allocated to read one of nine possible vignettes. All were accompanied by a picture of a police officer, either unarmed or carrying one of the three weapons (baton, CS spray, Taser). ${ }^{5}$ For the weapon conditions, participants were also presented with a description and image of the relevant weapon. ${ }^{6}$

After reading the vignette, participants were asked to make judgements about whether they thought the tactic used by the police officer was acceptable by indicating on a scale from 1 Strongly Disagree to 5 Strongly Agree how much they agreed with the statements: 'To what extent do you agree that another police officer would have behaved like this police officer in this situation?'; and 'To what extent do you agree that the way the police officer behaved was Wrong?'. ${ }^{7}$ The two items formed a reliable scale $(\alpha=.70)$.

\section{Study 1: Method}

\footnotetext{
${ }^{5}$ We reasoned that the photographs would provide a visual cue underlining the nature of the tactic being used.

${ }^{6}$ All study materials have been uploaded to a secure OSF site.

${ }^{7} \mathrm{We}$ also included a question on justifiability in all three studies. This item was not fielded to respondents in the 'talking down' condition as it was hard to imagine anyone thinking that action unjustified, so we do not use it here. Additional analysis suggested that when appropriate it produced identical outcomes to those we report.
} 
Police use of force

\section{Participants}

Study 1 participants were recruited via Prolific on 5 November 2019. The final sample comprised 788 participants, who were roughly representative of the UK adult population (apart from an over-representation of younger adults, see Table 1).

[Table 1 here]

\section{Measures}

Trust and legitimacy were measured using a series of 5-point agree/disagree scales.

Confirmatory factor analysis in the package Mplus 8 was used to derive and validate latent variables for analysis. All observed indicators were set to ordinal, and full information maximum likelihood estimation was used (see Appendix A for a list of the items used, factor loadings and model fit). Eight items measured procedural justice, police effectiveness and whether police operate within appropriate boundaries and were combined into a composite measure of trust in the police. Six items measured the two components of police legitimacy: normative alignment and duty to obey, also combined into a single composite measure.

Because Study 1 was interested in whether exposure to different police use of force tactics affected trust and legitimacy judgements, these measures were presented to participants after reading the vignette and, together with acceptability judgements, form the dependent variables for this study.

\section{Study 1: Results}

\section{Main Effects of Police Tactic and Use of Force}

First, we ran a 5 (police tactic: talking down, handcuffs, baton, CS spray, and Taser) x 2 (use of force: actual use of force, threat to use force) ANOVA to assess the effects of the experimental conditions on participants' acceptability judgements [H1]. Descriptive statistics 
Police use of force

are presented in Table 2 .

[Table 2 here]

\section{Police tactic effect}

There was a significant main effect of police tactic $(F(3,626)=8.21, p<.001)$. Post hoc tests showed that participants thought talking down $(M=4.32, S D=.69)$ and using handcuffs $(M=4.33, S D=.74)$ were both more acceptable ways for the officer to deal with the incident in the vignette, compared to using the baton $(M=3.93, S D=.95)$, CS spray $(M=3.98, S D=.87)$, or Taser $(M=3.88, S D=.99)$. There were no significant differences between the three weapon conditions: participants thought the use of baton, CS spray, and Taser were equally acceptable.

\section{Use of force effect}

There was a significant main effect of use of force $(F(1,626)=4.57, p=.033)$. Collapsed across all police tactic conditions (the talking down scenario was excluded from this analysis because use of force was not applicable), threat to use force $(M=4.11, S D=.89)$ was deemed more acceptable than actual use of force $(M=3.95, S D=.93)$. There was no significant interaction between police tactic and use of force $(F(3,626)=.65, p=.580)$, indicating that judgements of appropriateness did not vary by tactic.

\section{Effect of Condition on Trust and Legitimacy}

Next, to answer $\mathrm{H} 2$, we conducted a series of linear regressions to test whether police tactic and use of force conditions predicted subsequent perceptions of police. The experimental conditions were entered into the models as independent variables (talking down was the reference category); trust and legitimacy were the dependent variables. We found no 
Police use of force

significant effect of condition on participants' perceptions of trust and legitimacy (see Table 3). ${ }^{8}$ In other words, exposure to an incident involving police use of force (including the use of different weapons) did not change how participants viewed the police, at least in terms of their trust and legitimacy judgements.

[Table 3 here]

\section{Study 1: Discussion}

Study 1 demonstrated that police tactic mattered to judgements of acceptability. First, participants thought that talking down and using handcuffs to physically restrain the man in the vignette was more acceptable than using a weapon. Second, threatening to use force was more acceptable than the actual use of force, irrespective of the tactic involved. Finally, although we found that judgements about police action varied as a function of tactic and use of force, exposure to armed tactics and the application of force did not result in a loss of trust and legitimacy. However, as argued above it could be that the way people view incidents of police use of force are shaped by their prior perceptions. Therefore, in Study 2 we replicate Study 1 , but we include trust and legitimacy as independent variables.

\section{Study 2: Method}

The design, materials, and measures adopted in Study 2 were identical to those of Study 1. The critical difference in the procedure between the two studies is that in Study 2, participants were given the trust and legitimacy measures before reading the vignette.

Furthermore, in this study we also test three potential sources of trust and legitimacy, and reactions to police use of force: police identification, belief in a just world, and authoritarian attitudes.

\footnotetext{
${ }^{8}$ There was one significant result: those in the CS spray/use of force condition had significantly lower perceptions of police legitimacy compared to the talking down condition, but this finding seems likely to be a Type 1 error, given the consistency of the other results.
} 
Police use of force

\section{Participants}

Study 2 participants were recruited via Prolific on 5 November 2019. The final sample comprised 793 participants. Again, these participants were roughly representative of the UK adult population apart from an over-representation of younger adults (see Table 1).

\section{Measures}

Three additional measures were used in Study 2. Again, confirmatory factor analysis in the package Mplus 8 was used to derive and validate latent variables for analysis (see Appendix A). Police identification was measured using three items. Belief in a just world was measured using five items. Authoritarian attitudes were measured using two items. All items were measured on a 5-point agree/disagree scale. The trust and legitimacy measures were constructed using the same items as Study 1.

\section{Study 2: Results}

\section{Main Effects of Police Tactic and Use of Force}

We ran the same 2 (police tactic: handcuffs, baton, CS spray, and Taser) x 2 (use of force: actual use of force, threat to use force) plus 1 (talking down) ANOVA as Study 1. Descriptive statistics are presented in Table 2.

\section{Police tactic effect}

Consistent with Study 1, there was a significant main effect of police tactic $(F(3,632)=8.60$, $p<.001)$. Post hoc tests showed that participants thought that talking down $(M=4.21, S D=.73)$ and using handcuffs $(M=4.34, S D=.73)$ were both more acceptable ways for the officer to deal with the incident in the vignette, compared to using the baton $(M=3.88, S D=.94)$. Using handcuffs was also deemed more acceptable than using the CS spray $(M=3.98, S D=.91)$ and the Taser $(M=3.98, S D=.86)$. Interestingly, and unlike Study 1, there were no significant 
Police use of force

differences in acceptability between talking down and using the CS spray and the Taser. There were no significant differences between the three weapon conditions: participants thought the use of baton, CS spray, and Taser were equally acceptable.

\section{Use of force effect}

Unlike Study 1, there was no significant main effect of use of force $(F(1,632)=1.59, p=.207)$. In other words, collapsed across all police tactic conditions (not including participants in the talking down condition), whether the police officer actually used force or only threatened it made no difference to participants' judgements about whether the officer's actions were acceptable (use of force: $M=4.09, S D=.89$; threat to use force: $M=4.00, S D=.86$ ).

Furthermore, there was no significant interaction between police tactic and use of force $(F(3$, $632)=1.33, p=.264)$.

\section{Trust and Legitimacy as Predictors of Judgements About Police Action}

To address H3 we specified a Structural Equation Model (SEM) in the package Mplus 8 to test whether participants' judgements about the police officer's actions in the vignette were determined by their prior levels of trust and legitimacy. We also tested three potential predictors of both trust and legitimacy and reactions to use of force, and specified a structural model that investigated direct and indirect pathways. The model included police identification, belief in a just world, and authoritarian attitudes as exogenous variables, trust in the police and police legitimacy as mediating variables, and judgements of acceptability as the outcome variable. ${ }^{9}$ All latent variables in the model were regressed on contact with the police, and the two experimental

\footnotetext{
9 We used a single item measure of acceptability (To what extent do you agree that the way the police officer behaved was wrong?) due to issues associated with including both items of acceptability in our SEM model (standardized item loading of acceptability item $1>1$ ).
} 
Police use of force

conditions (tactic and use of force). ${ }^{10}$ The model produced fit indices of similar adequacy to the measurement model. Figure 1 shows the specified model, with standardized regression coefficients.

[Figure 1 here]

The model demonstrated that police identification, belief in a just world and authoritarian attitudes were associated with greater trust and legitimacy. In turn, trust (but not legitimacy) predicted judgements of acceptability. Trust in the police fully mediated the associations between police identification $(b=.25, p=.015)$, belief in a just world $(b=.08$, $\mathrm{p}=.024)$, and acceptability. There was also a significant direct statistical effect of authoritarian attitudes on acceptability - those with a more authoritarian mindset were less likely to find use of force 'wrong'- but neither trust nor legitimacy played a mediating role here. Acceptability judgements were therefore strongly predicted by prior perceptions of the police, but only in relation to the dimension of trust. Net of this, police legitimacy was not a significant predictor of acceptability.

\section{Discussion}

This paper presented two online experiments that explored police use of force. Among our orginal hypotheses, H1 was supported. We found that people drew a distinction between police tactics that involved the use of force with a weapon (baton, CS spray, Taser) and those that did not (talking down, handcuffs). Tactics that did not involve a weapon were judged more acceptable, but there were no differences across the three weapon conditions. H2 was not supported: exposure to different police tactics - including those that involved the actual

\footnotetext{
${ }^{10}$ We repeated these analyses controlling for participant characteristics (e.g. ethnicity) and the results remained consistent.
} 
Police use of force

use of force- had no knock-on effects on trust and legitimacy. Finally, H3 was supported. People who trusted the police were more accepting of the officer's actions. Legitimacy did not have the same effect. Study 2 also showed that police identification and political ideology were associated with trust, legitimacy and judgements about police use of force.

\section{Theoretical and Practical Implications}

There are a number of theoretical and practical contributions arising from this research. First, respondents seem to 'prefer' the use of handcuffs (and of course talking down) to the application of force via the use of tools such as batons, chemical sprays and Taser. Consistent with the ideology of British policing that centers on an unarmed constabulary, participants in our studies reacted more negatively to scenarios that transgressed this norm. Yet the differences here are not great, and the message seems to be that the mode of force delivery, and indeed its very application, do not comprise significant boundary points in views of police. Indeed, in a deliberately ambiguous situation, most respondents were prepared to support the officer's action, whatever form it took.

Of note is that we did not include a firearms option in this study. It would have made little sense to do so in the British context. It would be highly unlikely armed officers would be summoned to the scenario presented, and even if they were, even more unlikely the suspect would have been shot. We suspect if we had included such a scenario, respondents would have reacted strongly against it. There are normative limits to the police use of force, that is, but they were simply not reached for many of the respondents in the studies presented here. One likely reason for this relates to our second contribution, which is the finding that trust was associated with greater acceptance of the use of force. This fits with a growing literature (Bradford et al., 2017; Jackson and Gerber, 2017; Milani, 2020) demonstrating an association between favorable pre-existing attitudes toward the police and a greater 
Police use of force

acceptance of use of force, whether or not it seems normatively justified. Conversely, a lack of trust prompts a negative construal of police actions and a readiness to believe the wrong thing was done.

Our third contribution is to echo other recent work (Milani, 2020) by showing that exposure to vignettes involving the use of force does not appear to have a negative impact on public attitudes toward the police. Participants' attitudes remained unaffected, on average, by news of police use of force, irrespective of the tactic concerned. One interpretation of this finding is that trust and legitimacy are resilient, and, in some respects deeply embedded judgements of police. Beliefs about the legitimacy of police and their ability to successfully carry out their duties might also fit within a broader story about identity, group membership, politics and ideology, and may not be drastically impacted by what is seen as 'necessary' within the day-to-day remit of effective law enforcement (c.f. Nagin \& Telep, 2020).

While this may seem surprising given the recent protests across the UK, US, and elsewhere, it should be said that, in general, police activity typically occupies a very small portion of the attention of the average individual, and, moreover, incidents of force are far from the quotidian experience. Sparing, mundane, and low-level encounters comprise the vast bulk of interactions between police and public (Jackson et al., 2013), and in all likelihood will have characterized the experiences of most of our respondents here (who were surveyed prior to the world-wide spread of the Black Lives Matter movement). The extent to which use of force incidents inform people's judgements when they have other 'background' experiences of policing is still unclear. It is also the case that a relatively weak, one-off treatment does little to replicate the complexity and intensity of the real world (see limitations section below). How and when trust and legitimacy are renegotiated is a topic that still requires further exploration. 
Police use of force

Our study has thus shed light on how the use of force is processed and received, at least among this British sample. It seems judgements about police activity run on something of a one-way street. On the one hand, pre-existing levels of trust and legitimacy predispose people to assess police actions in particular ways; on the other hand, reading about the use of force does not erode trust and legitimacy. This may contextualize the long-standing affinity large sections of the British public feel with the police, in spite of highly publicized incidences of police malpractice (Bowling et al. 2019), and why news of excessive force does not seem to mobilize any great attitudinal or institutional shift. It will tend to be discounted by people who trust police, and taken to confirm the fears of those who do not.

\section{Limitations and Future Directions}

We finish by discussing some of the limitations of the current research and possible avenues for the future. First, the above claims must be qualified by the nature of the studies, which allow only a snapshot into respondents' perceptions of trust and legitimacy. It is possible the use of force bears a more accretive impact, or that its impact was insufficiently captured by a treatment clearly confined to the artificial parameters of an experimental study.

Second, there are the typical concerns about the reliability, generalizability and validity of the data, as a result of using a non-probability convenience sample recruited from a crowdsourcing platform, and also due to the self-report format and sensitive subject matter, which can be affected by social desirability and other response biases. Although the sampling methodology we used is common in the study of public attitudes towards the police (e.g. Gerber and Jackson, 2017), the over-representation of younger adults in our sample means the results may not be representative of the general population. Additionally, by virtue of the nature of the research, experimental conditions and fictional vignette scenarios can hardly replicate real instances of police use of force, and the conclusions drawn here do not provide 
Police use of force

the full texture or complexity of meaning behind the acceptance of force. Future investigation should explore these topics from a more robust methodological perspective.

Finally, we recommend researchers delve further into the idea that legitimacy and trust are 'conducive', but also constraining (Gerber and Jackson, 2017), to police power; and that these attitudes appear to remain unaffected by stories of use of force. Examining this from a longitudinal design could better elucidate the public's seemingly resilient relationship to the police, and the 'puzzle' identified by Bradford and colleagues (2017: 2) of 'why well publicized acts of police violence often fail to trigger wider or deeper challenges to the role and position of the police.' We also acknowledge the possibility of omitted variable bias. For example, future work should include measures of racial prejudice which might be an important predictor of attitudes about police use of force (c.f. Johnson and Kuhns, 2009).

$\underline{\text { Acknowledgements }}$ 
Police use of force

\section{References}

Bolger, P.C., and Walters, G.D. (2019). The relationship between police procedural justice, police legitimacy, and people's willingness to cooperate with law enforcement: A meta-analysis. Journal of Criminal Justice 60: 93-99.

Bowling, B., Reiner, R., and Sheptycki, J. (2019). The politics of the police, $5^{\text {th }}$ edition. Oxford, Oxford University Press.

Bradford, B., Milani, J., and Jackson, J. (2017). Identity, legitimacy and 'making sense' of police use of force. Policing: An International Journal 40(3): 614-627.

Bradford, B., Murphy, K., and Jackson, J. (2014). Officers as mirrors: Policing, procedural justice and the (re) production of social identity. British Journal of Criminology 54(4): 527-550.

Brodeur, J. P. (2010). The policing web. Oxford: Oxford University Press.

Chandler, J., and Paolacci, G. (2017). Lie for a Dime: When most pre-screening responses are honest but most study participants are impostors. Social Psychological and Personality Science 8: 500-508.

College of Policing (2020). Officer and Staff Safety Review. Available from: https://paas-s3broker-prod-lon-6453d964-1d1a-432a-9260-5e0ba7d2fc51.s3.eu-west2.amazonaws.com/s3fs-public/2020-09/CoP-NPCC-Officer-Staff-Safety-Review.pdf [Accessed 22 Oct 2020]

Dalbert, C., Montada, L., and Schmitt, M. (1987). Belief in a just world: Validation correlates of two scales. Psychologische Beitrage 29: 596-615

Gerber, M.M., and Jackson, J. (2017). Justifying violence: legitimacy, ideology and public support for police use of force. Psychology, Crime \& Law 23(1): 79-95.

Heath, A., Evans, G., and Martin, J. (1994). The measurement of core beliefs and values: The development of balanced Socialist/Laissez Faire and Libertarian/Authoritarian Scales. British Journal of Political Science 24(1): 115-132.

Home Office (2019a). Police use of force statistics, England and Wales: April 2018 - March 2019. Available from: https://www.gov.uk/government/statistics/police-use-of-forcestatistics-england-and-wales-april-2018-to-march-2019 [Accessed 10 Feb 2020].

Home Office (2019b). Police use of firearm statistics, England and Wales: April 2018 to March 2019. Available from: https://www.gov.uk/government/statistics/police-useof-firearms-statistics-england-and-wales-april-2018-to-march-2019 [Accessed 11 Feb 2020]. 
Police use of force

Jackson, J., Bradford, B., Stanko, B., and Hohl, K. (2013). Just authority? Trust in the police in England and Wales. Oxon: Routledge.

Jackson, J., and Gau, J. M. (2016). Carving up concepts? Differentiating between trust and legitimacy in public attitudes towards legal authority. In Interdisciplinary perspectives on trust (pp. 49-69). Springer, Cham.

Johnson, D., and Kuhns, J. B. (2009). Striking out: Race and support for police use of force. Justice Quarterly 26: 592-623.

Kahneman, D. (2011). Thinking, fast and slow. Macmillan.

Jonathan-Zamir, T. Mastrofski, S.D. and Moyal, S. (2015) Measuring procedural justice in police-citizen encounters, Justice Quarterly, 32(5): 845-871

Lammy, D. (2017). The Lammy review. London: Lammy Review. Available from: https://www.gov.uk/government/publications/lammy-review-final-report [Accessed 10 Feb 2020].

Loader, I., and Mulcahy, A. (2003). Policing and the condition of England: memory, politics and culture. Oxford University Press on Demand.

Milani, J. (2020). Political Ideology, Racism, and American Identity: An Examination of White Americans' Support for the Police Use of Excessive Force. Unpublished doctoral thesis, University of Oxford.

Nagin, D.S., and Telep, C.W. (2017). Procedural justice and legal compliance. Annual Review of Law and Social Science, 13: 5-28.

Nagin, D.S. \& Telep, C.W. (2020). Procedural Justice and Legal Compliance. Criminology and Public Policy, 19:761-786.

Nix J. (2020). On the challenges associated with the study of police use of deadly force in the United States: A response to Schwartz \& Jahn. PloS one, 15(7).

Oliveira, T.R., Jackson, J., Bradford, B., and Murphy, K. (2019). Are trustworthiness and legitimacy 'hard to win, easy to lose'? A longitudinal test of the asymmetry thesis of police-citizen contact. Journal of Quantitative Criminology.

Perry, G., Jonathan-Zamir, T., and Weisburd, D. (2017). The effect of paramilitary protest policing on protestors' trust in the police: The case of the "Occupy Israel" movement. Law \& Society Review 51(3): 602-634.

Radburn, M., Stott, C., Bradford, B., and Robinson, M. (2018). When is policing fair? Groups, identity and judgements of the procedural justice of coercive crowd policing. Policing and Society 28(6): 647-664. 
Police use of force

Roché, S., and Roux, G. (2017). The 'silver bullet' to good policing: A mirage. An analysis of the effects of political ideology and ethnic identity on procedural justice. Policing an International Journal 40(3): 514-528.

Silver, J., and Pickett, J. (2015). Toward a better understanding of politicized policing attitudes: Conflicted conservatism and support for police use of force. Criminology 53(4): 650-676.

Stoutland, S.E. (2001). The multiple dimensions of trust in resident/police relations in Boston. Journal of Research in Crime and Delinquency 38(3): 226-256.

Tankebe, J. (2013). Viewing things differently: The dimensions of public perceptions of police legitimacy. Criminology: An Interdisciplinary Journal, 51(1): 103-135.

Tankebe, J. (2009) Public cooperation with the police in Ghana: Does procedural fairness matter? Criminology 47(4): 1265-1293.

Trinkner, R., Jackson, J., and Tyler, T.R. (2018). Bounded authority: Expanding "appropriate" police behavior beyond procedural justice. Law and Human Behavior 42(3): 280-293.

Tyler, T.R. (2006). Why people obey the law. Princeton, NJ: Princeton University Press.

Tyler, T.R. (2011). Trust and legitimacy: Policing in the USA and Europe. European Journal of Criminology 8(4): 254-266.

Tyler, T.R., and Huo, Y. (2002). Trust in the law: Encouraging public cooperation with the police and courts. New York: Russell Sage Foundation.

Yesberg, J.A., and Bradford, B. (2019). Affect and trust as predictors of public support for armed police: Evidence from London. Policing and Society 29(9): 1058-1076. 
Police use of force

\section{Appendix A}

Item wordings and factor loadings for latent variables used in analysis

\begin{tabular}{|c|c|c|}
\hline & \multicolumn{2}{|c|}{ Factor loadings } \\
\hline & Study 1 & Study 2 \\
\hline \multicolumn{3}{|l|}{ Trust in police } \\
\hline $\begin{array}{l}\text { Procedural justice (Jackson et al., 2013) } \\
\text { The police make decisions based on facts }\end{array}$ & 0.731 & 0.798 \\
\hline The police explain their decisions to the people they deal with & 0.703 & 0.736 \\
\hline The police treat people with respect & 0.828 & 0.836 \\
\hline \multicolumn{3}{|l|}{ Effectiveness (Jackson et al., 2013) } \\
\hline The police are effective at responding to emergencies promptly & 0.488 & 0.528 \\
\hline \multicolumn{3}{|l|}{ Bounded authority (Trinkner et al., 2018) } \\
\hline When the police deal with people they almost always behave according to the law & 0.848 & 0.847 \\
\hline When the police deal with people they almost always respect people's rights & 0.870 & 0.891 \\
\hline The police often arrest people for no good reason (reverse coded) & 0.723 & 0.701 \\
\hline
\end{tabular}

\section{Police legitimacy}

Obligation to obey (Trinkner et al., 2018)

I feel a moral obligation to obey the police

$\begin{array}{ll}0.718 & 0.777 \\ 0.604 & 0.677\end{array}$

I feel a moral duty to support the decisions of police officers, even if I disagree with them

I feel a moral duty to obey the instructions of police officers, even when I don't understand the reasons behind them

0.668

Normative alignment (Trinkner et al., 2018)

I support the way the police usually act

The police usually act in ways that are consistent with my own ideas about what

0.844

0.886

is right and wrong

0.893

0.879

The police stand up for values that are important for people like me

0.913

I identify with the police

0.908

I feel a sense of solidarity with the police

0.803

I feel similar to the police

\section{Belief in a just world (Dalbert et al., 1987)}

I am confident that justice always prevails over injustice

I think that basically the world is a just place

I am confident that, in the long run, people will be compensated for injustices

I firmly believe that injustices in all areas of life (e.g., professional, family,

\begin{tabular}{ll}
\hline Authoritarian attitudes (Heath et al., 1994) & \\
People who break the law should be given stiffer sentences & 0.706 \\
Schools should teach children to obey authority & 0.874 \\
\hline
\end{tabular}

Fit indices Study 1: $\chi^{2}(70)=416.70, \mathrm{p}<.001 ;$ RMSEA $=0.08[.07, .09] ;$ CFI $=0.98 ;$ TLI $=0.98$

Fit indices Study $2: \chi^{2}(240)=1256.52, p<.001 ;$ RMSEA $=0.07[0.07,0.08] ;$ CFI $=0.97 ;$ TLI $=0.96$ 
Police use of force

Table 1. Participant characteristics.

\begin{tabular}{llcccc}
\hline \multirow{2}{*}{ Characteristic } & & Study 1 & \multicolumn{3}{c}{ Study 2} \\
& & $\%$ & $\mathrm{~N}$ & $\%$ & $\mathrm{~N}$ \\
\hline Gender & Male & 50.0 & 396 & 49.4 & 388 \\
& Female & 50.0 & 396 & 50.6 & 397 \\
Age range & $18-24$ & 15.4 & 122 & 15.0 & 118 \\
& $25-44$ & 57.3 & 454 & 59.3 & 455 \\
& $45-64$ & 24.3 & 193 & 23.3 & 183 \\
\multirow{5}{*}{ Ethnicity } & $65+$ & 3.0 & 24 & 2.3 & 18 \\
& White & 90.7 & 717 & 88.2 & 692 \\
& Asian & 5.8 & 46 & 6.0 & 47 \\
& Black & 1.5 & 12 & 2.5 & 20 \\
& Mixed & 1.3 & 10 & 2.7 & 21 \\
\multirow{5}{*}{ Country of birth } & Other & 0.8 & 6 & 0.6 & 5 \\
& UK & 88.5 & 701 & 87.9 & 689 \\
& Not- & 11.5 & 91 & 12.1 & 95 \\
\hline
\end{tabular}

*Percentages calculated with missing values excluded 
Police use of force

Table 2. Descriptive statistics for judgement of police action by use of force condition.

\begin{tabular}{lllcccc}
\hline Judgement of police & Police tactic & Use of force & \multicolumn{2}{c}{ Study 1} & \multicolumn{2}{c}{ Study 2} \\
\cline { 3 - 6 } action & condition & condition & $M$ & $S D$ & $M$ & $S D$ \\
\hline Acceptability & Handcuffs & Use of force & 4.43 & .69 & 4.19 & .83 \\
& & Threat only & 4.25 & .75 & 4.47 & .61 \\
& \multirow{2}{*}{ Baton } & Use of force & 3.83 & .96 & 3.82 & .93 \\
& & Threat only & 3.94 & .90 & 4.03 & .97 \\
& \multirow{2}{*}{ CS spray } & Use of force & 4.11 & .93 & 3.94 & .88 \\
& \multirow{2}{*}{ Taser } & Threat only & 3.86 & .88 & 4.03 & .87 \\
& & Use of force & 4.01 & .86 & 3.87 & 1.04 \\
& & Threat only & 3.97 & .87 & 3.90 & .95 \\
\hline
\end{tabular}


Police use of force

Table 3. Study 1 OLS regression - experimental condition predicting trust and legitimacy

\begin{tabular}{lllll}
\hline & \multicolumn{3}{c}{ Trust } & \multicolumn{3}{c}{ Legitimacy } \\
\cline { 2 - 5 } & $\mathrm{B}$ & $\mathrm{SE}$ & $\mathrm{B}$ & $\mathrm{SE}$ \\
\hline Experimental condition (ref: talking down) & & & & \\
Handcuffs/Force used & -.09 & .10 & -.05 & .11 \\
Handcuffs/Threat only & .01 & .10 & .02 & .11 \\
Baton/Force used & -.10 & .10 & -.11 & .11 \\
Baton/Threat only & .06 & .10 & .08 & .11 \\
CS Spray/Force used & -.17 & .10 & $-.23 *$ & .10 \\
CS Spray/Threat only & -.04 & .10 & -.05 & .11 \\
Taser/Force used & .15 & .10 & .20 & .11 \\
Taser/Threat only & -.07 & .10 & .02 & .11 \\
\hline
\end{tabular}

$* \mathrm{p}<.05$ 
Police use of force

1
2
3
4
5
6
7
8
9
10
11
12
13
14
15
16
17
18
19
20
21
22
23
24
25
26
27
28
29
30
31
32
33
34
35
36
37
38
39
40
41
42
43
44
45
46
47
48
49
50
51
52
53
54
55
56
57
58
59
60


Police use of force

Figure 1. Study 2 SEM with acceptability as the ultimate response variable

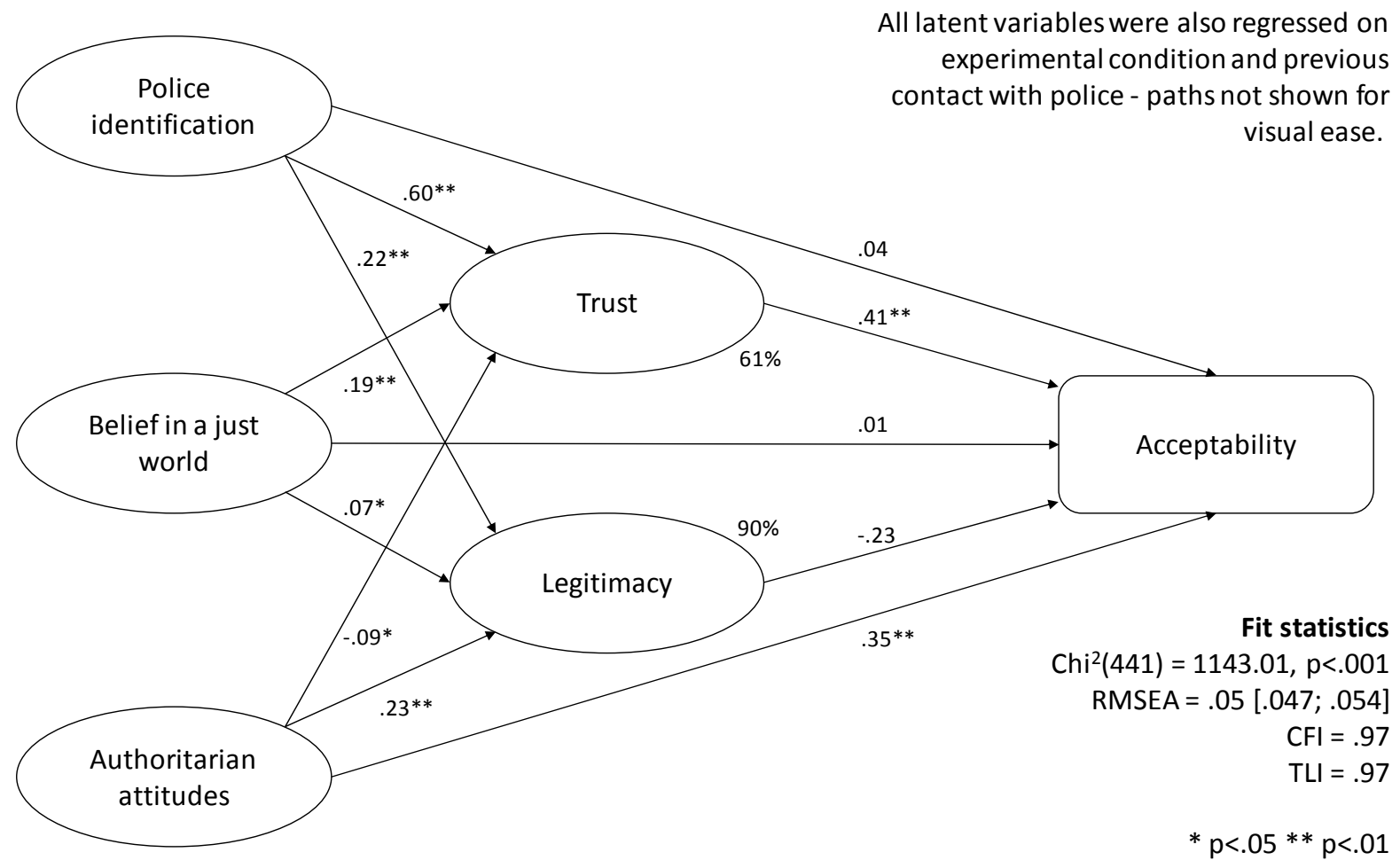

